\title{
Análise e avaliação das políticas públicas: seu impacto no desenvolvimento local em Angola
}

Analysis and evaluation of Public Policies: impact on local development in Angola

Análisis y evaluación de Políticas Públicas: sus repercusiones en el desarrollo local en Angola

Carlos dos Santos Teixeira*

\section{Resumo}

Em Angola, o Plano Nacional de Desenvolvimento 2013-2017 constitui um dos principais repositórios de políticas públicas para Angola. As principais linhas de força do Orçamento Geral do Estado angolano para 2014, aponta o Sector Social como aquele que mais diretamente pode reflectir ma melhoria das condições de vida da população, absorvendo uma fatia de $1 / 3$ do orçamento. As políticas públicas das áreas da Saúde, Educação e Assistência Social, adoptadas pelo Executivo Angolano, podem ser consideradas como um exemplo para a promoção do desenvolvimento local. No entanto, desafios persistem no quadro da desconcentração financeira do Estado e da autonomia plena dos municipios, como forma de induzir o desenvolvimento econômico local e a maior participação dos actores locais na agenda do desenvolvimento nacional.

Palavras-chave: Políticas Públicas. Desenvolvimento Local. Desempenho Governamental.

\section{Introdução às políticas públicas}

O tratamento deste tema tem como objectivo geral a abordagem das políticas públicas, sua concretização setorial, por via da análise e avaliação no quadro da oportunidade que o dossiê da revista do Mestrado e Doutorado em História de poder e governação, sobre Brasil e Angola: redes nos proporcionam. A abordagem desse tema: análise

Professor Associado da Faculdade de Direito e Director do Centro de Pesquisa em Politicas Públicas e Governação Local - Universidade Agostinho Neto. Luanda, Angola. E-mail: cteixeira1611@hotmail.com

Recebido em 17/11/2014 - Aprovado em 25/03/2015 http://dx.doi.org/10.5335/hdtv.15n.1.5274 
e avaliação de políticas públicas, impõe-nos o envolvimento das instituições de ensino e investigação no debate desses assuntos num espaço público e democrático, analisando os desafios e as potencialidades das políticas públicas de uma Angola em franco crescimento.

Trata-se, pois, de um tema cujo conhecimento se revela importantíssimo e cujo debate sobre a sua racionalidade impõe-se amiúde. Entretanto, não podemos falar de políticas públicas, mesmo circunscrita a concretude do espaço que se chama Angola, sem antes fazermos uma revisão de natureza histórica, ainda que telegraficamente. Assim, convocaríamos desde logo a referência que se tornaria lapidar, feita pelo cientista politico norte-americano Hugh Heclo que no seu Model Social Politico in Britain and Sueden, em 1974, escreveu que "as decisões politicas radicam não apenas no poder, mas, também, na incerteza, nos homens colectivamente a pensarem quais as decisões a tomar" acrescentado que "os governos não se limitam a exercer o poder, criam puzzle colectivo em nome da sociedade. Implica, ao mesmo tempo, decidir e saber".

É, pois, seguindo esse fio condutor que nos propomos aqui e agora, enquanto académicos discorrer sobre os caminhos desse conhecimento avaliando o seu impacto, potenciando uma relação mais próxima entre este saber sobre as políticas públicas e exercício ou confirmação do poder, por outras palavras, potenciando os decisores para as melhores e mais racionais opções e escolhas políticas. A par do debate nas academias, é também em sede dos mais mediáticos que se realiza o debate público informado assente em critérios racionais de apresentação e confronto de alternativas políticas.
Nesta ordem de ideias, parece-me não ser despiciendo chamar a colação na abordagem feita a respeito pelo antigo Presidente dos Estados Unidos da América Bill Clinton quando disse: "o que é bom para política não funciona necessariamente no mundo real, onde o que funciona é a cooperação". É pois assumindo a nossa responsabilidade na contribuição para esse conhecimento que quero conjuntamente lançar a nossa pedra para incorporação na formação, concretização, monitorização e avaliação das politicas publicas entre nós, contribuindo para reforçar a sua qualidade e bem fundando das opções, no quadro de escolhas politicas competitivas entre si.

A constatação de que Angola apesar de estar em franco crescimento económico, tem, entretanto, uma economia pouco diversificada em que o sector petrolífero representa ainda cerca de $45 \%$ na estrutura do Produto Interno Bruto, $60 \%$ das receitas fiscais representado por conseguinte mais de $90 \%$ das exportações, expondo a economia Angolana aos choques da economia internacional.

\section{Formação de Políticas Públicas}

O Plano Nacional de Desenvolvimento 2013-2017 constitui um dos principais repositórios de políticas públicas para Angola, estando nele escalpelizados os objectivos nacionais de médio e longo prazo, destacando-se dentre eles os seguintes:

1. Preservação da unidade e coesão nacional.

2. Garantia dos pressupostos básicos necessários ao desenvolvimento.

3. Melhoria de qualidade de vida.

4. Inserção da juventude na vida activa. 
5. Desenvolvimento do sector privado.

6. Inserção competitiva de Angola no contexto internacional.

Com os objectivos descritos, quais são então as políticas públicas nacionais de desenvolvimento? O tempo disponível para a preparação do presente artigo, não nos permitirá discorrer sobre todas elas. Vamos por conseguinte, escolher algumas que pela sua actualidade e impacto justificam a meu ver sua a eleição para sua abordagem aqui e agora.

\section{Política da População}

Sendo a população e o homem angolano os pontos de convergência de todos os resultados políticos e acções de promoção do desenvolvimento que se preconizam, contribuirá para uma melhor definição o Recenseamento Geral da População e da habitação realizado no mês de Maio de 2014 e cujos resultados sairão brevemente a público.

Como não se pode falar de população sem olhar para família, o Plano Nacional de Desenvolvimento, preconiza a sua valorização, através de várias formas de apoio, visando criar as condições económicas, sociais, culturais e políticas, para que ela possa desenvolver a sua função nuclear na sociedade, da qual é a célula base, sempre com respeito da identidade, unidade, autonomia e valores tradicionais.

Ainda nesta perspectiva, a acção do Poder Executivo, está voltada para uma política de igualdade de género que promova, para homens e mulheres iguais oportunidades, direitos e responsabilidades em todos os domínios da vida económica, política e social. A prestação de serviços voltados para o atendimento das necessidades básicas do idoso, em que as famílias, a sociedade e as entidades governamentais e não-governamentais participam.

Enquadra-se ainda nas políticas públicas de valorização da população, a protecção integral dos direitos das crianças, de modo a que ela desfrute de modo pleno, efectues e permanente dos princípios reconhecidos nas leis nacionais e nos tratados internacionais de que o País é parte.

Os movimentos migratórios internos e externos, em termos de políticas públicas, devem igualmente ser balizados pela Estratégia Nacional do Desenvolvimento e na Politica Nacional de População.

Política de Modernização do Sistema de Defesa e Segurança Nacional

Dissemos no início da nossa abordagem, que um dos objectivos de politicas públicas nacionais assentam na preservação da unidade e coesão nacional. Tal só é possível se os pressupostos fundamentais da defesa e da Segurança Nacional, estiverem alicerçados quer na perspectiva interna, quer externa como condição sine qua non para a estratégia de reforço da democracia e da promoção do desenvolvimento nacional, devidamente inserido SADC e em outras organizações regionais de que o País é membro, assim como em África ${ }^{1}$ e no mundo.

Para o efeito, constituem prioridades de políticas públicas no domínio:

- A revisão da legislação fundamental sobre Defesa Nacional e Forças Armadas.

- Melhoria da qualidade e capacidade técnica, operacional logística e infra estruturas das Forças Armadas. 
- Elevação da qualidade técnica e profissional dos recursos humanos das Forças Amadas, bem como a melhoria das mas condições de vida

- Revisão da legislação fundamental sobre segurança e Ordem Interna.

- Garantir a Segurança Pública e a Integridade e Controlo das Fronteiras Nacionais e Combater a Criminalidade.

- Elaborar a qualidade técnica e profissional dos recursos humanos das Forças de Segurança.

Política de Reforma Tributária e das Finanças Públicas

Enquadram-se nos objectivos de políticas públicas neste domínio:

- Desenvolver um sistema tributário mais eficiente na arrecadação de receitas, que seja mais simples nos procedimentos e justa para o contribuinte e ajustado aos objectivos de desenvolvimento económico e social de Angola.

- Introduzir mecanismos eficazes na cobrança, que salvaguardem os direitos e garantias dos contribuintes.

- Implementação de serviço ao contribuinte de excelência, por via do necessário investimento nas tecnologias de informação e comunicação e modernização das práticas, metodologias e processos.

- Melhorar a qualidade e eficiência da administração tributária, através do recrutamento e selecção de pessoal qualificado e realização de acções de formação continua, a nível nacional e local, preconizando-se a criação do Instituto de Formação Tributária.

- Harmonizar o sistema tributário angolano com melhores práticas internacio- nais, quer no contexto regional, como global, por via da celebração progressiva de acordos de cooperação com instituições e organismos internacionais.

Política de Promoção do Crescimento Económico, do Aumento do Emprego e de Diversificação da Economia

A constatação de que Angola apesar de estar em franco crescimento económico, tem entretanto uma economia pouco diversificada em que o sector petrolífero representa ainda cerca de $45 \%$ na estrutura do Produto Interno Bruto, $60 \%$ das receitas fiscais representado por conseguinte mais de $90 \%$ das exportações, expondo a economia Angolana aos choques da economia internacional.

Perante este cenário vêm, sendo desenvolvidas acções de políticas públicas com vista a promoção de diversificação da estrutura económica, avançada pelo investimento público, proporcionando ao sector privado um papel de motorização economia por via do empoderamento do empresariado nacional.

\section{Promoção e Diversificação da Estrutura}

Económica Nacional

O forte esforço de investimento público na reabilitação e desenvolvimento das infraestruturas constitui uma medida de política pública de apoio ao desenvolvimento e criação de empregos, proporcionando:

- A promoção da competitividade e o desenvolvimento sustentável dos vários sectores da actividade económica, no quadro das prioridades de desenvolvimento territorial.

- Asseguramento e coordenação entre investimentos públicos e privados, de forma a criar as condições necessárias para 
o desenvolvimento de agrupamentos industriais (clusters) e redes empresariais, aumentando o valor acrescentado e potenciado a criação de externalidades positivas para a economia.

Promoção do Emprego e Capacitação e Valorização dos Recursos Humanos Nacionais

Os desafios do desenvolvimento de Angola e o contexto de globalização e mobilidade internacional da força de trabalho, impõe medidas de política públicas, que proporcionem aos angolanos um papel chave no desenvolvimento do País, abarcando a melhoria de qualidade de vida dos cidadãos, a inserção da juventude no mercado de trabalho, catalizando o desenvolvimento do empresariado nacional, assim como a inserção competitiva de Angola no Contexto internacional.

Neste contexto deverão ser desenvolvidas as seguintes medidas de políticas públicas prioritárias:

- Incentivo a criação de emprego produtivo, qualificado e enumerador condigno para todos os angolanos em idade actual.

- Elaboração e Implementação da Estratégia Nacional de Desenvolvimento de Recursos Humanos.

- Implementação do Plano Nacional de Formação de Quadros, como instrumento de execução da estratégia Nacional de Formação de quadros e parte da estratégia Nacional de Desenvolvimento de recursos Humanos, preparando os angolanos para concorrer pelos postos de trabalho que exijam as mais qualificações.
- Incentivar a Formação Contínua.

- Estimular a Modernização da Organização do Trabalho.

Análise Estratégica de Políticas Públicas

A análise estratégica de políticas públicas funda-se basicamente em documentos do planeamento e prestação de contas do Estado, designadamente:

- O Plano estratégico

- O Plano de Actividades

- O Orçamento Geral do Estado

- O Relatório de Actividades

\subsubsection{Plano Estratégico}

Neste documento, tal como já tivemos oportunidade de referenciar, defini-se a estratégia de médio/longo prazo. É no dizer de Jorge Caldeira ${ }^{2}$ um documento "Sonho" nem sempre qualificado objectivamente na sua ambição.

O Plano Estratégico deve ser um documento dinâmico que deve reflectir a aprendizagem gerada pela elaboração do Plano de Actividades, da Monitorização, do Relatório de Actividades e de outros impactos importantes que venham a ter lugar no período da sua execução.

O Plano Estratégico é um documento, cuja responsabilidade da produção é da liderança de topo da organização. Considerando que planear é prever, a curto, médio e longo prazos, metas objectivas e recursos; estamos pois perante um instrumento que não é de negligenciar para uma obra humana seja mais facilmente exequível. 


\section{Plano de Actividades}

É um documento importantíssimo na gestão dos negócios públicos com um horizonte temporal de 1 ano, que define os objectivos a atingir e a estratégia a seguir, hierarquizando iniciativas, programando acções e mobilizando recursos. Para a elaboração deste documento participam as chefias intermédias e da organização.

\section{0rçamento Geral do Estado}

O Orçamento Geral do Estado é o principal instrumento da política económica e financeira do Estado Angolano que, expresso em termos de valores, para um período de tempo definido, demonstra o programa de operações a realizar e determinar as suas fontes de financiamento. Por outras palavras, o Orçamento Geral do Estado, não é mais do que a quantificação financeira da ambição proposta pelo Plano.

As principais linhas de força do Orçamento Geral do Estado angolano para 2014, aponta o Sector Social, como aquele que mais directamente pode reflectir ma melhoria das condições de vida da população, absorvendo uma fatia de $\mathbf{1 / 3}$ do orçamento. Para aferir o seu impacto no desenvolvimento local e considerando a sua afectação por província vide o quadro que se segue:

Tabela 1: Afectação dos Recursos por Província

\begin{tabular}{|c|c|c|}
\hline Província & Valor Kz & $\%$ \\
\hline Bengo & 35140079597,00 & $0,48 \%$ \\
\hline Benguela & 90026222097,00 & $1,24 \%$ \\
\hline Bié & 62741703354,00 & $0,86 \%$ \\
\hline Cabinda & 52081433586,00 & $0,72 \%$ \\
\hline Cuando Cubango & 62172110820,00 & $0,86 \%$ \\
\hline Cuanza Norte & 31662951944,00 & $0,44 \%$ \\
\hline Cuanza Sul & 47876631402,00 & $0,66 \%$ \\
\hline Cunene & 36853691507,00 & $0,51 \%$ \\
\hline Estrutura Central & 6144771111833,00 & $84,66 \%$ \\
\hline Exterior & 31819694098,00 & $0,44 \%$ \\
\hline Huambo & 75580735481,00 & $1,04 \%$ \\
\hline Huíla & 70821698009,00 & $0,98 \%$ \\
\hline Luanda & 208418839849,00 & $2,87 \%$ \\
\hline Lunda Norte & 37786831608,00 & $0,52 \%$ \\
\hline Lunda Sul & 34668958613,00 & $0,48 \%$ \\
\hline Malange & 50406046750,00 & $0,69 \%$ \\
\hline Moxico & 57629877951,00 & $0,79 \%$ \\
\hline Namibe & 33543085952,00 & $0,46 \%$ \\
\hline Uíge & 58565594763,00 & $0,81 \%$ \\
\hline Zaire & 35817260748,00 & $0,49 \%$ \\
\hline Total Geral & 7258384559944,00 & $100 \%$ \\
\hline
\end{tabular}

Fonte: Boletim Informativo do Governo de Angola. 
Da tabela acima, pode-se depreender que há ainda desafios decorrentes da desconcentração financeira, com um peso de $84,66 \%$ recaindo sobre os sectores de nível central. A província de Luanda, considerada como a mais populosa apresenta uma cifra em torno de 2,87\%. Não obstante esta consideração há um assinalável salto qualitativo e quantitativo em termos de recursos alocadas a nível das provinciais e municípios. A municipalização dos serviços de educação e saúde são marcos de boas práticas em termos de desconcentração sectorial e proximidade dos serviços públicos junto ao cidadão.

\section{Relatório de Actividades}

É o documento que relata o percurso e ou o estado de progresso da execução do Plano e ou Programa, nomeadamente no que tinge a avaliação do grau de concretização dos objectivos e iniciativa previstas ${ }^{3}$. Sequencialmente estes documentos apresentam - se - nos da seguinte forma.

$1^{\mathrm{a}}$ Fase - Estudo para elaboração do plano estratégico

$2^{\mathrm{a}}$ Fase - Formulação do Plano Estratégico

$3^{\mathrm{a}}$ Fase - Implementação

$4^{\mathrm{a}}$ Fase - Acompanhamento / Monitorização

$5^{\mathrm{a}}$ Fase - Prestação de Contas

\section{Critérios de Avaliação de Políticas Públicas}

Os critérios de avaliação de políticas públicas podem ser quantitativas ou qualitativas. Entretanto alguns autores incorporam outros critérios, tal como a caiação de valor, situando-se num quadro que se caracteriza pelos seguintes factores:
- Pressão

- Exigências crescentes na qualidade do serviço

- Necessidade de melhoria de desempenho

- Rapidez das mudanças

- Complexidade Crescentes

- Criação Efectiva de valor

- Sustentabilidade

Eficiência e Efectividade de Políticas Públicas

A análise deste item comporta a demarcação de indicadores de resultados medidos em concreto com o alcançar das performances preconizadas com o objectivo estratégico. Quais são os indicadores que podem ser utilizados para medir os objectivos estratégicos?

É difícil responder em termos exactos a essa questão, pois nem sempre é possível atribuir o melhor ou melhores indicadores. Entretanto a melhor doutrina sobre a análise e avaliação de políticas públicas costuma catalogara título meramente exemplificativo, alguns indicadores, tais sendo:

- Taxa de qualidade de serviço

- Taxa de reclamação à qualidade do serviço

- Percentual de redução de custos

- Valor das novas receitas

- Melhoria de processos

- Índice de competências

- Taxa de cumprimento do plano de formação para aumento de competências

- Índice de motivação

- Taxa de implantação dos valores 
Efectividade de Politicas Públicas em Angola

As políticas públicas das áreas da Saúde, Educação e Assistência Social adoptadas pelo Executivo Angolano, podem ser consideradas como um exemplo para a promoção do desenvolvimento local. No entanto desafios persistem no quadro da desconcentração financeira do Estado e autonomia plena dos municipios.

Grandes avançados foram dados em sectores vitais da vida social e económica do país. Novas centralidades estão emergindo em quase todo o País. Compõem a nova centralidade de Cabinda, com 1002 habitações, dos quais 618 são do tipo T4 e as restantes 384 são do tipo T3 e todos dotados de infraestruturas básicas. No sector social, 972.046 é o número de registos civis praticados no $1^{\circ}$ Trimestre de 2014, sendo 365.771 dos 0 aos 13 anos, 310.334 dos 14 anos em diante. Foram criados um total de 158.891 postos de emprego criados em Angola durante o ano de 2013.

Número de ligações de água ao domicílio efectuadas pela EPAL em Luanda no âmbito do programa das 700 mil ligações. Um percentual de 58,35\% corresponde à taxa de cobertura do programa água para todos e, em nível nacional, 13,3 milhões do número de usuários de telefones móveis. Os serviços notariais praticaram 128.887 actos no I Trimestre de 2014, sendo 17.653 procurações, 10.765 escrituras diversas, 23.765 autenticações e 76.704 reconhecimentos.

\section{Considerações finais}

O Estudo das políticas públicas constitui um vector fundamental para promover o desenvolvimento local. São as políticas pú- blicas que orientam a acção governamental a nível sectorial e a nível local. Em Angola, as políticas públicas são elaboradas para resolver problemas identificados por vários agentes públicos e cidadãos anónimos, na perspectiva do contributo à harmonização social, a atender os efeitos da guerra desarticulou a economia, reduziu a pouco ou quase nada as actividades produtivas, especialmente a agricultura, provocou a migração interna e aumentou o desemprego. As políticas são orientadas pata a estabilidade, o crescimento e o emprego constituem o eixo principal das políticas públicas, dos planos e programas de acção do Governo angolano

A complexidade dos problemas que a sociedade enfrenta e os desafios decorrentes das mudanças conjunturais e estruturais, leva a um debate quanto a eficácia na implementação das Políticas públicas. Este confronto implica analise dos caminhos actuais e a sua efectividade em diferentes esferas da vida nacional com destaque para o papel da ciência na dinamização de soluções tendentes a melhoria continua do desempenho das políticas pública e da acção governamental. O Executivo de Angola tem adoptado políticas e programas consistentes com a visão de que a estabilidade macroeconómica, os planos de educação e formação de quadros e da mão de obra nacional, as medidas activas de emprego adaptadas à conjuntura, as acções de fomento e dinamização dos sectores da vida económica e social do país.

A par do debate nas academias, é também em sede dos mais mediáticos que se realiza o debate público informado assente em critérios racionais de apresentação e confronto de alternativas políticas. A academia 
desempenha um papel vital na dinamização das políticas públicas em Angola. É assim que a Universidade Agostinho Neto, através do CPPPGL, procura desenvolver competências e habilidades técnicas-analíticas em políticas públicas visando proporcionar uma profunda e sólida formação e uma compreensão teoricamente consubstanciada sobre as grandes questões da administração e gestão que afectam as organizações governamentais e não-governamentais, bem como aprofundar as habilidades práticas no desenvolvimento de políticas, planeamento e gestão.

\section{Abstract}

In Angola, the National Development Plan 2013 - 2017, is one of the main repositories of public policies for Angola. The main thrust of the general budget of the Angolan State for 2014, says the social sector, such as the one that can directly reflect ma improving people's living conditions, taking a slice $1 / 3$ of the budget. Public policies in the areas of Health, Education and Social Assistance adopted by the Angolan executive, can be considered as an example for the promotion of local development. However challenges remain in the context of financial decentralization of the state and full autonomy of municipalities as a way to induce local economic development and greater involvement of local actors in the national development agenda.

Keywords: Public Policies. Local Development. Government Performance.

\section{Resumen}

En Angola, El Plan Nacional de Desarrollo 2013 - 2017, es uno de los principales depositarios de las políticas públicas de Angola. El principal objetivo del presupuesto general del Estado angoleño para el 2014, dice que el sector social, como la que puede reflejar directamente ma mejorar las condiciones de vida de las personas, teniendo una rebanada tercio del presupuesto. Las políticas públicas en las áreas de Salud, Educación y Asistencia Social adoptadas por el Ejecutivo angoleño, se pueden considerar como un ejemplo para la promoción del desarrollo local. Sin embargo sigue habiendo problemas en el contexto de la descentralización financiera del Estado y la plena autonomía de municipios como una forma de inducir el desarrollo económico local y una mayor participación de los actores locales en el programa nacional de desarrollo.

Palabras clave: Políticas Públicas. Desarrollo Local. Desempeño del Estado.

\section{Notas}

\footnotetext{
União Africana.

Balanced Scorecard no Estado, 2010, p. 14.

O acompanhamento de actividades e iniciativas previstas não é mais do que um processo de monitorização de organização para garantir a boa execução do plano estratégico e actividades.
}

\section{Referências}

Balanced Scorecard no Estado, Almedina; 2010. 